\title{
Tissue mimicking materials for a multi-imaging modality prostate phantom
}

\author{
Warren D. D'Souza, a) Ernest L. Madsen, Orhan Unal, Karl K. Vigen, Gary R. Frank, \\ and Bruce R. Thomadsen \\ Department of Medical Physics, University of Wisconsin, Madison, Wisconsin 53706
}

(Received 7 July 2000; accepted for publication 8 January 2001)

\begin{abstract}
Materials that simultaneously mimic soft tissue in vivo for magnetic resonance imaging (MRI), ultrasound (US), and computed tomography (CT) for use in a prostate phantom have been developed. Prostate and muscle mimicking materials contain water, agarose, lipid particles, protein, $\mathrm{Cu}^{++}$, EDTA, glass beads, and thimerosal (preservative). Fat was mimicked with safflower oil suffusing a random mesh (network) of polyurethane. Phantom material properties were measured at $22{ }^{\circ} \mathrm{C}$. $\left(22{ }^{\circ} \mathrm{C}\right.$ is a typical room temperature at which phantoms are used.) The values of material properties should match, as well as possible, the values for tissues at body temperature, $37^{\circ} \mathrm{C}$. For MRI, the primary properties of interest are $\mathrm{T} 1$ and $\mathrm{T} 2$ relaxations times, for US they are the attenuation coefficient, propagation speed, and backscatter, and for CT, the x-ray attenuation. Considering the large number of parameters to be mimicked, rather good agreement was found with actual tissue values obtained from the literature. Using published values for prostate parenchyma, $\mathrm{T} 1$ and $\mathrm{T} 2$ at $37^{\circ} \mathrm{C}$ and $40 \mathrm{MHz}$ are estimated to be about 1100 and $98 \mathrm{~ms}$, respectively. The CT number for in vivo prostate is estimated to be $45 \mathrm{HU}$ (Hounsfield units). The prostate mimicking material has a T1 of $937 \mathrm{~ms}$ and a T2 of $88 \mathrm{~ms}$ at $22^{\circ} \mathrm{C}$ and $40 \mathrm{MHz}$; the propagation speed and attenuation coefficient slope are $1540 \mathrm{~m} / \mathrm{s}$ and $0.36 \mathrm{~dB} / \mathrm{cm} / \mathrm{MHz}$, respectively, and the CT number of tissue mimicking prostate is $43 \mathrm{HU}$. Tissue mimicking (TM) muscle differs from TM prostate in the amount of dry weight agarose, $\mathrm{Cu}^{++}$, EDTA, and the quality and quantity of glass beads. The $18 \mu \mathrm{m}$ glass beads used in TM muscle increase US backscatter and US attenuation; the presence of the beads also has some effect on T1 but no effect on T2. The composition of tissue-mimicking materials developed is such that different versions can be placed in direct contact with one another in a phantom with no long term change in US, MRI, or CT properties. Thus, anthropomorphic phantoms can be constructed. (C) 2001 American Association of Physicists in Medicine.
\end{abstract}

[DOI: $10.1118 / 1.1354998]$

Key words: phantom, tissue mimicking, MRI, ultrasound, CT, prostate

\section{INTRODUCTION}

There has been a tremendous surge in the number of ultrasound (US) guided transperineal radioactive prostate implants for cancer treatment performed in recent years. Threedimensional multi-modality images used in combination with one another might enhance the effectiveness of treatment planning. A multi-modality anthropomorphic prostate imaging phantom with representative values of critical parameters for MRI, CT, and US could aid in the development of effective multi-modality treatment planning. Phantom materials that mimic three human soft tissues regarding magnetic resonance imaging (MRI), ultrasound, and computed tomography $(\mathrm{CT})$ properties have been developed for use in an anthropomorphic prostate region phantom. The three tissues mimicked are prostate parenchyma, skeletal muscle, and adipose tissue (fat).

Tissue mimicking (TM) materials must exhibit properties at room temperature which are comparable to those of the parenchymal type represented at body temperature since phantoms must be useful at room temperature. For example, TM materials for use in magnetic resonance imaging phantoms should have $\mathrm{T} 1$ and $\mathrm{T} 2$ values at $22^{\circ} \mathrm{C}$ which correspond to those of the tissue at body temperature and at the
Larmor frequency of concern. Published T1 and T2 relaxation times for relevant human tissue parenchymae at or near body temperature are shown in Table I. ${ }^{1-8}$

TM materials for use in ultrasound should have the same ranges of propagation speeds, attenuation coefficients, and backscatter coefficients as the mimicked soft tissue type. Ultrasound propagation speeds and attenuation values for human skeletal muscle and subcutaneous abdominal fat and breast fat are shown in Tables II $^{9-13}$ and III ${ }^{14-18}$ respectively. Data for prostate tissue could not be found in the literature, so values for the liver gland are given as possibly relevant.

For use in computed tomography $(\mathrm{CT})$, the TM materials should exhibit the same linear attenuation coefficient or CT number as that of the tissue being mimicked. The CT numbers for most soft tissues (excluding fat) lie in the range of about 20-90 at the typical effective x-ray energy of a clinical CT scanner with fat having a CT number of about -100 . Table IV shows the CT numbers for in vivo human tissues at a mean energy of $62 \mathrm{keV}$ (Ref. 19) and $78 \mathrm{keV}$ (mean energy supplied by manufacturer). The $78 \mathrm{keV}$ values were determined from six patient CT scans.

Phantoms for use in MRI systems, made from waterbased agarose gels along with a copper salt, have been de- 
TABLE I. Published NMR relaxation time (T1 and T2) data for relevant human soft tissues. Data are adapted from Ref. 8.

\begin{tabular}{|c|c|c|c|c|c|c|}
\hline $\begin{array}{c}\text { Human tissue } \\
\text { type }\end{array}$ & $\begin{array}{c}\text { Temperature } \\
\left({ }^{\circ} \mathrm{C}\right)\end{array}$ & $\begin{array}{c}\text { In } \\
\text { vivo? }\end{array}$ & $\begin{array}{c}\text { Frequency } \\
(\mathrm{MHz})\end{array}$ & $\mathrm{T} 1$ (ms) & $\mathrm{T} 2(\mathrm{~ms})$ & Reference \\
\hline \multirow[t]{2}{*}{ prostate } & 40 & no & 20 & 808 & 98 & Grodd et al. ${ }^{1}$ \\
\hline & 37 & yes & 64 & 1022 (range $822-1351)$ & $\cdots$ & Kjaer et ll. $^{2}$ \\
\hline \multirow[t]{3}{*}{ muscle } & 37 & yes & 6 & $\cdots$ & $47 \pm 3$ & LeBlanc et $a l .^{3}$ \\
\hline & 37 & yes & 15 & $514 \pm 138$ & $32 \pm 7$ & Ehman et al. ${ }^{4}$ \\
\hline & 37 & no & 43.5 & $650-800$ & $\cdots$ & Borghi et $a l .^{5}$ \\
\hline \multirow[t]{3}{*}{ fat } & 37 & yes & 12 & $209 \pm 17$ & $135 \pm 16$ & Just et al. ${ }^{6}$ \\
\hline & 37 & yes & 15 & $266 \pm 45$ & $57 \pm 3$ & Nyman et al. $^{7}$ \\
\hline & 40 & no & 20 & $192 \pm 26$ & 108 & Grodd et al. ${ }^{1}$ \\
\hline
\end{tabular}

scribed previously. ${ }^{20}$ The $\mathrm{T} 1$ and $\mathrm{T} 2$ relaxation rates in these materials are strongly dependent on the concentrations of agarose and copper ions in the TM sample with the T1 depending more on the copper and the $\mathrm{T} 2$ depending more strongly on the concentration of dry weight agarose.

We recently reported that various mixtures of aqueous gelatin and agar with $\mathrm{Cu}^{++}$and Ethylenediaminetetraacetic acid tetrasodium hydrate (EDTA) could control T1 and T2 values to match in vivo values. ${ }^{21}$ The concentration of agar controls primarily $\mathrm{T} 2$ and the concentration of $\mathrm{Cu}^{++}$-EDTA controls T1. The EDTA is required to form a stable free molecule with $\mathrm{Cu}^{++}$preventing the $\mathrm{Cu}^{++}$from being bound to the gelatin and, hence, made ineffective for reducing $\mathrm{T} 1$.

The possibility of developing materials which mimic soft tissues simultaneously for ultrasound, MRI, and computed tomography (CT) arose when a new TM material was developed for ultrasound in which the attenuation property is controlled through the concentration of condensed milk. ${ }^{22}$ Ultrasonic propagation speeds and frequency-dependent attenuation coefficients are already well approximated by these materials. Ultrasound backscatter coefficients (echogenicity) can be controlled by adding small concentrations of $45-53 \mu \mathrm{m}$ diameter glass beads scatterers. ${ }^{22}$ Trial samples of a TM material consisting of a mixture of $54 \%$ condensed milk and $46 \%$ agarose solution (3\% dry weight) resulted in $\mathrm{T} 1=1366 \pm 27 \mathrm{~ms}$ and $\mathrm{T} 2=62.1 \pm 0.2 \mathrm{~ms}$ at $22^{\circ} \mathrm{C}$, again in the range of soft tissues, thus indicating the suitability of these materials for mimicking tissue MRI properties as well as ultrasound properties.

Long-term stability aspects have also been addressed since the TM materials reported here will be used in the construction of an anthropomorphic prostate phantom where materials representing different soft tissues (at least prostate, muscle, and fat) and containing different concentrations of their components will be in direct contact. This raises the question of whether long-term diffusion of water solutes between regions of different composition will result in changing NMR (nuclear magnetic resonance), ultrasound, and/or $\mathrm{x}$-ray properties of the TM materials. To study this possibility, sets of three test phantoms were constructed each of which was half-filled with one type of TM material and the other half with another type. Control phantoms each filled with only one type of TM material were also produced. The MRI, ultrasound, and CT properties of the materials in these phantoms were then monitored.

\section{MATERIALS AND METHODS OF PRODUCTION OF TISSUE MIMICKING MATERIALS}

The compositions of the tissue mimicking materials are given in Table V. Mimicking nonfat soft tissue involves an appropriate choice of concentrations of agarose, gelatin, $\mathrm{Cu}^{++}$, and EDTA (in aqueous solution). After a series of iterations involving varying the concentrations of condensed milk, dry weight agarose, $\mathrm{Cu}^{++}$, and EDTA, we were able to match the $\mathrm{T} 1$ and $\mathrm{T} 2$ relaxation rates, the ultrasonic speed and attenuation coefficients, and CT numbers with those of human skeletal muscle and prostate.

The prostate and muscle mimicking materials contain agarose (Product \#A0169, Sigma Chemical Company, St. Louis, MO), condensed milk, distilled water deionized to 18 $\mathrm{M}-\Omega, n$-propyl alcohol, $\mathrm{CuCl}_{2}$ salt, EDTA (chelating agent), and thimerosal (preservative). $\mathrm{Cu}^{++}$-EDTA lowers $\mathrm{T} 1$. Thimerosal prevents bacterial invasion. Very small diameter

TABLE II. Published US propagation speeds for human soft tissues at body temperature relevant to a prostate phantom. Ultrasound propagation speed and attenuation values were not found for prostate in the literature. Propagation speeds for another common gland, the liver, are given.

\begin{tabular}{lcccl}
\hline \hline Human tissue type & Temperature $\left({ }^{\circ} \mathrm{C}\right)$ & In vivo? & Speed of sound $(\mathrm{m} / \mathrm{s})$ & \multicolumn{1}{c}{ Reference } \\
\hline skeletal muscle & 37 & yes & 1580 & Sollish et al. ${ }^{9}$ \\
breast fat & 37 & no & 1436 & Rajagopalan et al. ${ }^{10}$ \\
subcutaneous fat & 35 & no & 1476 & Bullen et al. ${ }^{11}$ \\
liver & 37 & yes & 1578 & Robinson et al. $^{12}$ \\
liver & 37 & yes & 1593 & Bamber et al. ${ }^{13}$ \\
\hline \hline
\end{tabular}


TABLE III. Compilation of US attenuation coefficients for human soft tissues relevant to a prostate phantom.

\begin{tabular}{|c|c|c|c|c|c|}
\hline $\begin{array}{c}\text { Human tissue } \\
\text { type }\end{array}$ & $\begin{array}{c}\text { Temperature } \\
\left({ }^{\circ} \mathrm{C}\right)\end{array}$ & In vivo? & $\begin{array}{c}\text { Frequency } \\
(\mathrm{MHz})\end{array}$ & $\begin{array}{c}\text { Attenuation } \\
\text { coefficient } \\
\div \text { frequency } \\
(\mathrm{dB} / \mathrm{cm} / \mathrm{MHz})\end{array}$ & Reference \\
\hline breast fat & 37 & no & 5 & 0.49 & D'Astous et al. ${ }^{14}$ \\
\hline breast fat & 37 & no & 6 & 0.55 & D'Astous et al. ${ }^{14}$ \\
\hline breast fat & 37 & no & 7 & 0.62 & D'Astous et al. ${ }^{14}$ \\
\hline fat & 37 & no & 5 & 0.46 & Dussick et al. ${ }^{15}$ \\
\hline muscle & 37 & yes & 4.3 & $1.10 \pm 0.10$ & Ophir et al. ${ }^{16}$ \\
\hline liver & 37 & yes & 2.5 & 0.45 & Parker et al. ${ }^{17}$ \\
\hline liver & 37 & yes & 3 & 0.50 & Taylor et al. ${ }^{18}$ \\
\hline
\end{tabular}

microscopic glass beads were added to the material mimicking muscle to augment the ultrasound attenuation and backscatter level. The differences between materials mimicking prostate and muscle are the dry weight concentrations of agarose and the inclusion of glass beads in the material mimicking muscle. Fat was adequately mimicked with pure safflower oil suffusing a polyurethane mesh (network) (pore size 14, FOAMEX, Eddystone, PA). (This polyurethane mesh is a form of the air filtration material commonly used in window air conditioners.)

The process of making 1 liter of TM prostate is as follows. First, $2 \mathrm{~g}$ of thimerosal is dissolved in 1 liter of condensed milk (Diehl Co., Defiance, $\mathrm{OH}$ ) and the solution is passed through $17 \mu \mathrm{m}$ and then $10 \mu \mathrm{m}$ mesh filters (Tetko, Inc., Kansas City, MO) to remove any impurities that may have been introduced in prior concentrating and packaging. (Whole milk is condensed by ultrafiltration at Diehl, Inc., Defiance, OH. The volume of permeate is $\frac{2}{3}$ of the initial whole milk volume. The condensed milk contained none of the additives usually present in commercially available condensed milk.) Next, 79 cc of $n$-propanol, 1 liter of $18 \mathrm{M}-\Omega$ deionized water, and $20 \mathrm{~g}$ of dry agarose are combined in a beaker at room temperature and the mixture is heated in a $95^{\circ} \mathrm{C}$ water bath until the agarose solution clears. The molten agarose solution is then cooled to $55^{\circ} \mathrm{C}$ while the condensed milk is heated to that temperature. Then $500 \mathrm{cc}$ of agarose solution is added to $500 \mathrm{cc}$ of condensed milk to make a $50-50$ volume mixture. The mixture is stirred to uniformity and any air bubbles are removed from the surface. Then $1.03 \mathrm{~g}$ of EDTA (Aldrich Chemical Co., Inc., Milwaukee, WI) and $0.6 \mathrm{~g}$ of $\mathrm{CuCl}_{2} \cdot 2 \mathrm{H}_{2} \mathrm{O}$ (Mallinckrodt,

TABLE IV. CT numbers for in vivo human soft tissues relevant to a prostate phantom.

\begin{tabular}{lcc}
\hline \hline Human soft tissue & $\begin{array}{c}\text { CT no. at mean } \\
\text { photon energy of 62 } \\
\mathrm{keV}^{\mathrm{a}}\end{array}$ & $\begin{array}{c}\text { CT no. at 78 keV } \\
(133 \mathrm{kVp}) \text { on Siemens } \\
\text { CT scanner }\end{array}$ \\
\hline Prostate & not measured & $45 \pm 17$ \\
Muscle & 59 & $77 \pm 14$ \\
Adipose & -114 & $-97 \pm 9$ \\
\hline
\end{tabular}

${ }^{2}$ Data are from Fullerton et al. ${ }^{19}$

${ }^{\mathrm{b}}$ Means and standard deviations are on six human subjects; data from various positions on six subjects.
Inc., St. Louis, MO) are added and the mixture is again stirred sufficiently to ensure homogeneity. Then $1 \mathrm{~g}$ of 45-53 $\mu \mathrm{m}$ diameter glass beads (Potters Industries, Inc., Parsippany, NJ) is added and stirring repeated. [Glass beads were soaked for $24 \mathrm{~h}$ in concentrated nitric acid to remove any paramagnetic impurities from their surfaces (removes uncertainty in T1). The acid is rinsed off before use.] Care is taken to prevent the temperature of the final mixture from falling below $45^{\circ} \mathrm{C}$.

To form the "solid" form of the prostate mimicking material, the molten mixture is first cooled to $45^{\circ} \mathrm{C}$ by submersing the bottom part of the beaker in a cool water $\left(22^{\circ} \mathrm{C}\right)$ bath with stirring. Then the molten material is poured into the appropriate container and sealed from the atmosphere. The container is rotated at $2 \mathrm{rpm}$ about a horizontal axis to prevent gravitational sedimentation. One type of container is a test cylinder that allows monitoring of relevant properties of all three imaging modalities. Such a cylinder typically has a thickness of $2.5 \mathrm{~cm}$ and inner diameter of $7.6 \mathrm{~cm}$. The flat ends are covered with $25 \mu \mathrm{m}$ thick Saran Wrap (Dow Chemical, Midland, MI) epoxied to an acrylic cylinder with wall thickness $6 \mathrm{~mm}$. A polypropylene $10 \mathrm{cc}$ syringe barrel with the needle-coupling end cap cut off is epoxied into a

TABLE V. Composition of TM materials mimicking prostate, muscle, and fat tissues.

\begin{tabular}{|c|c|}
\hline Material & Composition of TM material \\
\hline TM-prostate & $\begin{array}{l}50 \% \text { (volume percent) condensed milk, } 50 \% \\
\text { (volume percent) agarose solution ( } 2 \% \text { dry } \\
\text { weight percent) and } 7.9 \mathrm{~cm}^{3} n \text {-propyl alcohol } \\
\text { per } 100 \mathrm{~cm}^{3} \text { agarose solution, } 0.103 \mathrm{~g} \mathrm{EDTA} \\
\text { per } 100 \mathrm{~cm}^{3} \text { of total volume, } 0.06 \mathrm{~g} \mathrm{CuCl}_{2} \text { per } \\
100 \mathrm{~cm}^{3} \text { of total volume, } 1 \mathrm{~g} / 1 \text { of } 45-53 \mu \mathrm{m} \\
\text { diameter glass beads }\end{array}$ \\
\hline TM-muscle & $\begin{array}{l}50 \% \text { (volume percent) condensed milk, } 50 \% \\
\text { (volume percent) agarose solution ( } 6 \% \text { dry } \\
\text { weight percent) and } 7.9 \mathrm{~cm}^{3} n \text {-propyl alcohol } \\
\text { per } 100 \mathrm{~cm}^{3} \text { agarose solution, } 0.082 \mathrm{~g} \mathrm{EDTA} \\
\text { per } 100 \mathrm{~cm}^{3} \text { of total volume, } 0.048 \mathrm{~g} \mathrm{CuCl} 2 \\
\text { per } 100 \mathrm{~cm}^{3} \text { of total volume, } 5 \mathrm{~g} \text { microscopic } \\
\text { glass beads per } 100 \mathrm{~cm}^{3} \text { total volume }\end{array}$ \\
\hline TM-fat & Pure safflower oil and polyurethane mesh \\
\hline Alternative TM-fat & Pure safflower oil \\
\hline
\end{tabular}


hole in the acrylic cylinder, providing a tube for pouring in the molten material. Flat acrylic constraining caps are placed over the ends of the cylinder and the syringe piston inserted with a wire temporarily in place so that all air is excluded from the volume of molten molten material. Rubber bands are placed over the end of the piston so that a positive gauge pressure is maintained during rotation at $2 \mathrm{rpm}$ about a horizontal axis during congealing.

TM muscle is made in a similar manner to TM prostate with the following compositional differences: (1) $60 \mathrm{~g}$ of dry agarose are added to a room temperature solution of $79 \mathrm{cc}$ $n$-propanol and $1000 \mathrm{cc}$ deionized water; (2) instead of 45 to $53 \mu \mathrm{m}$ beads, $50 \mathrm{~g}$ of glass beads with mean diameter $18 \mu \mathrm{m}$ are added to 1 liter of molten mixture; (3) $0.82 \mathrm{~g}$ of EDTA and $0.48 \mathrm{~g}$ of $\mathrm{CuCl}_{2}$ are added to 1 liter of molten mixture.

The first step in making TM fat is to cut a circular disc (7.6 $\mathrm{cm}$ diameter, $2.5 \mathrm{~cm}$ thick) of polyurethane mesh and place it in the test cylinder with the same inner dimensions. Safflower oil (The Hain Food Group, Inc., Uniondale, NY) is then poured into the test cylinder, filling the region not occupied by the polyurethane mesh. It is important that no air bubbles are trapped in the polyurethane mesh. An alternative TM fat is safflower oil only and is made by pouring the oil into the test cylinder with no polyurethane mesh present.

\section{A. Long-term stability phantoms}

In anthropomorphic prostate phantoms, it is critical that the three component materials, TM prostate, TM muscle, and TM fat, be in direct contact with one another since plastic or glass boundary layers would produce unacceptable artifacts in the images. The component materials must not suffer changes in physical properties (T1 and T2 values, US attenuation and propagation speeds, and CT numbers) due to diffusion of solutes or water across boundaries. Considerable effort was expended to adjust concentrations of materials so that such diffusion does not occur. Six test cylinders having the form shown in Fig. 1 were constructed. The test cylinders have a $6 \mathrm{~mm}$ thick acrylic curved wall and a $25 \mu \mathrm{m}$ thick layer of Saran Wrap over each end. The inner dimensions have a diameter of $10 \mathrm{~cm}$ and thickness of $2.5 \mathrm{~cm}$. Three control cylinders were made, one filled with TM prostate, another with TM muscle, and a third with safflower oil. The safflower oil represented TM fat; the presence of the polyurethane mesh was considered unnecessary for this test. The other three cylinders contain two different TM materials, each occupying a half cylinder as depicted in Fig. 1; the two materials are in direct contact, allowing diffusion of solutes between them to occur freely. The half-cylinder arrangement allows monitoring of US, MR, and CT properties over time to assess long-term changes. During manufacture of the latter three types of test cylinders, one material was introduced and allowed to congeal before the second material was introduced.

Since the dry weight agar in the TM muscle is about three times that in the TM prostate, resulting in a lower concentration of water in the former, it was surmised that the appropriate net $\mathrm{Cu}^{++}$-EDTA concentrations in TM muscle might be less than that in TM prostate. Thus, three of the

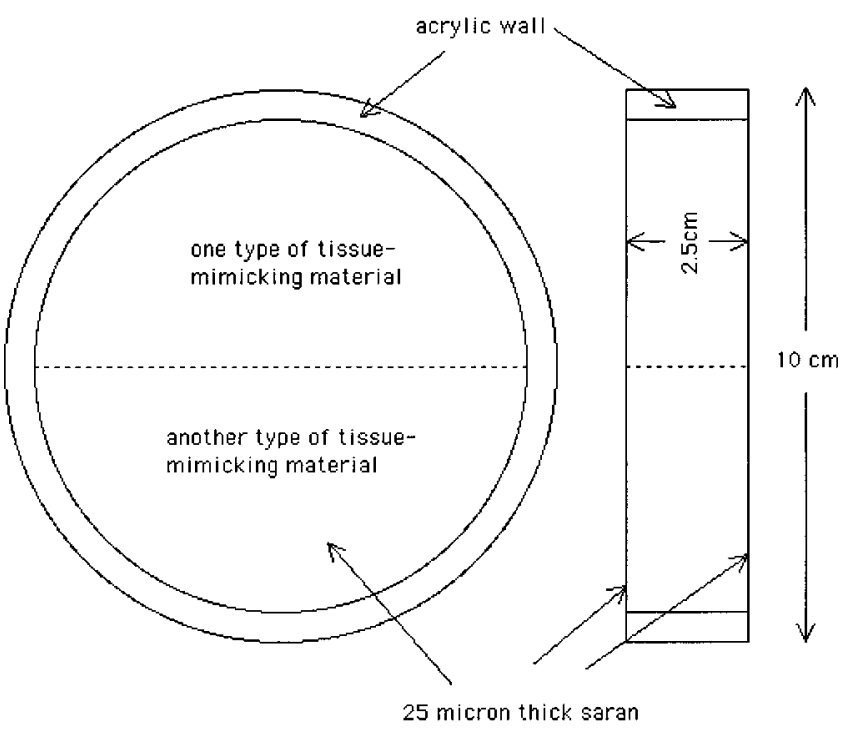

FIG. 1. Schematic representation of long-term stability phantom used to check if diffusion occurs across the boundaries of the TM materials.

two-TM-material cylinders were made with the $\mathrm{Cu}^{++}$-EDTA concentrations the same in each, and the other three were made with the $\mathrm{Cu}^{++}$-EDTA concentration in TM muscle reduced to $80 \%$ of that in the TM prostate. (Net concentration means the number of grams of material per unit volume of TM material.) The involved cylinders were the TM muscle control, the cylinder containing TM muscle and TM prostate and the cylinder containing TM muscle and alternative TM fat. The content of the long-term stability phantoms is shown in Table VI.

\section{MEASUREMENT APPARATUS AND METHODS}

\section{A. MRI}

The parameters of interest are hydrogen longitudinal and transverse relaxation times-T1 and T2, respectively. Small sample measurements were performed using a $40 \mathrm{MHz}$ Minispec relaxometer (Bruker, Canada) along with supporting equipment consisting of an IBM computer, a storage oscilloscope, and a constant temperature water bath maintained at a temperature of $2{ }^{\circ} \mathrm{C}$. The temperature of the spectrometer magnet and probe is maintained at $40{ }^{\circ} \mathrm{C}$. A small quantity of the molten form of each TM material was poured into a $5 \mathrm{~mm}$ diameter NMR tube and allowed to congeal. The small size provided for congealing in a few minutes, eliminating the need for rotation at $2 \mathrm{rpm}$. The tube was sealed with petrolatum to prevent dessication. In order to make measurements at about $22^{\circ} \mathrm{C}$, the NMR tube containing the

TABLE VI. Long-term stability phantoms.

\begin{tabular}{cc}
\hline \hline Phantom & Volume composition of phantom \\
\hline 1 & $50 \%$ TM prostate, $50 \%$ alternative TM fat \\
2 & $50 \%$ TM muscle, $50 \%$ alternative TM fat \\
3 & $50 \%$ TM prostate, $50 \%$ alternative TM muscle \\
\hline \hline
\end{tabular}


sample was placed in the $21{ }^{\circ} \mathrm{C}$ water bath until it reached the water temperature. The sample temperature rises during measurement, and the average temperature is estimated to be $22^{\circ} \mathrm{C}$. Data was acquired within 1 to $1.5 \mathrm{~min}$ before a significant temperature rise occurred. It has been shown that the temperature rise of the sample within the first minute is less than $2{ }^{\circ} \mathrm{C} .{ }^{23}$ The relaxometer was interfaced with the computer which uses software from IBM Instruments (Danbury, $\mathrm{CT}$ ) for pulse programming and data acquisition.

The inversion recovery (IR) sequence was used to obtain the data for the longitudinal relaxation time. A recovery time (TR) of at least five times the expected T1 was used, and the T1 experiment was repeated ten times for averaging. Data reduction was done by curve fitting using the relation

$$
M(t)=M_{0}(1-2 \exp (-t / \mathrm{T} 1)),
$$

where $M_{0}$ is the equilibrium longitudinal magnetization and $M(t)$ is the longitudinal magnetization at time $t$ following the $180^{\circ}$ pulse. The uncertainties in $M(t)$ values were determined and propagated to estimate the uncertainty in $\mathrm{T} 1 .^{24}$

The Carr-Purcell-Meiboom-Gill (CPMG) spin-echo pulse sequence was used to measure the transverse relaxation time T2. The relaxation delay (repetition time) was set to $7 \mathrm{~s}$ and data was acquired for $\tau$ values of of $25,125,250$, and $500 \mu$ s. (Different $\tau$ values were used to verify that the T2's determined are not significant functions of $\tau$.) Note that $2 \tau$ is the time between successive echoes. Two hundred fifty-five echo peaks were recorded in each CPMG sequence. The data obtained were fitted for each $\tau$ to the exponential form

$$
M(t)=M_{0} \exp (-t / \mathrm{T} 2),
$$

where $M(t)$ is the instantaneous transverse magnetization at time $t$, and $M_{0}$ is the initial equilibrium magnetization.

\section{B. Ultrasound}

Ultrasonic propagation speed and attenuation coefficients were measured on the cylindrical samples using the same apparatus for both properties. The basic idea is displacement of water while monitoring the change in the pulse arrival time and amplitude of through-transmission tone burst pulses. ${ }^{25}$ Adequate time is allowed for the samples to reach the $22^{\circ} \mathrm{C}$ temperature of the water bath before measurements were made. The parallel faces of the samples are maintained perpendicular to the ultrasound beam direction.

The propagation speed was determined by measuring the change in the pulse arrival time for the cases in which the sample is present and absent between the transmitting and receiving transducers. The propagation speed in the TM material sample was then calculated relative to the propagation speed in distilled water using the widely used relation

$$
c_{s}=\frac{c_{w}}{1-c_{w} \Delta t / d_{s}},
$$

where $c_{s}$ is the propagation speed in the sample, $c_{w}$ $=1489 \mathrm{~m} / \mathrm{s}$ is the propagation speed in $22^{\circ} \mathrm{C}$ distilled water, ${ }^{26} \Delta t$ is the change in pulse arrival time with insertion of the sample, and $d_{s}$ is the thickness of the sample.
The ultrasonic attenuation coefficients were determined at four discrete frequencies: 2.5, 4.5, 6.2, and 8.0 MHz. This determination was done by measuring pulse amplitudes when the sample was inserted in and absent from the path of the ultrasound beam. Corrections for transmission through thin plastic layers over the parallel sample faces are significant for frequencies above about $2 \mathrm{MHz}$ and are included in the data reduction. ${ }^{25}$ These corrections include the effect of different acoustic impedances of water and TM materials.

Simulation of relative backscatter levels of the TM materials is important, particularly in the 5 to $7 \mathrm{MHz}$ range where US prostate imaging is done. Qualitative observations of prostate ultrasound images indicate that the backscatter level is noticeably lower in prostate than in surrounding muscle, perhaps $6 \mathrm{~dB}$. The concentration of $45-53 \mu \mathrm{m}$ glass bead scatterers in the TM prostate was adjusted so that the TM prostate backscatter was $6 \mathrm{~dB}$ below that for the TM muscle determined using a $5 \mathrm{MHz}$ linear array (L) probe on an Acusan 128 XP scanner. The procedure was to use samples of the $2.5 \mathrm{~cm}$ thick test cylinders and scan them in the "dual" mode, adjusting the overall gain so that the mean brightness appeared the same for both samples. The difference in overall gain values for the two samples defines the relative backscatter level.

\section{C. $\mathrm{CT}$}

Ideally, the X-ray linear attenuation coefficient $\mu(E)$ at photon energy $E$ involves determination of received monochromatic x-ray bean intensity with $(I)$ and without $\left(I_{0}\right)$ a length $x$ of attenuating material in the beam. The linear attenuation coefficient is then given by solving the relation

$$
I=I_{0} e^{-\mu(E) x} .
$$

Monochromatic x-ray beams were not available, so standard filtered beams were used. Three different beam qualities available in the Accredited Dosimetry Calibration Laboratory (ADCL), at the University of Wisonsin-Madison, were employed. These x-ray beams are calibrated and traceable to the National Institute of Standards and Technology (NIST). The beam qualities used are designated M-150 and M-200 corresponding to the filtration used; they have mean photon energies of 67 and $100 \mathrm{keV}$, respectively. The M-150 x-ray beam is representative of a typical clinical CT beam. The $\mathrm{x}$-ray system (Advanced X-ray, Atlanta, GA) uses a $14 \mathrm{kHz}$ constant potential generator and has a tungsten anode with 3 $\mathrm{mm}$ inherent beryllium filtration.

The ratio of intensities with $(I)$ and without $\left(I_{0}\right)$ the test cylinder of TM materal in place is equal to the ratio of intensities each integrated over the same time interval $t$, which is equal to the ratio of charges monitored over that time period, $Q(t) / Q_{0}(t)$, collected with a spherical graphitewalled ion chamber (Far West Technology, Goleta, CA). The charge values were measured using an electrometer (Keithley Measurements, Inc., Cleveland, OH). The sample cylinder containing the TM material was placed in the x-ray 
TABLE VII. T1 relaxation times and uncertainties for TM materials measured at $22{ }^{\circ} \mathrm{C}$ on a $40 \mathrm{MHz}$ relaxometer. Compare with corresponding tissue T1 values in column five of Table $\mathrm{I}$.

\begin{tabular}{ll}
\hline \hline Sample & T1 (ms) \\
\hline TM prostate & $937 \pm 13$ \\
TM muscle & $686 \pm 9$ \\
Alternative TM fat & $207 \pm 6$ \\
\hline \hline
\end{tabular}

beam with its parallel faces perpendicular to the propagation direction of the $\mathrm{x}$-ray beam. The effective $\mathrm{x}$-ray linear attenuation coefficient, $\mu_{\mathrm{eff}}$, is found by solving

$$
Q(t)=Q_{0}(t) \exp \left(-\mu_{\text {eff }} x\right)
$$

for $\mu_{\text {eff }}$ where $x$ is the thickness of the sample. The measured parameter, $\mu_{\text {eff }}$, is the "effective" linear attenuation coefficient because the beam is not monoenergetic.

Clinically, the CT number of a TM sample may be of more relevance than $\mu_{\text {eff }}$ for characterizing the TM materials. The CT number was measured using a Siemens CT scanner at $133 \mathrm{kVp}$ with a mean energy of $78 \mathrm{keV}$ (mean energy supplied by manufacturer). The TM materials were scanned and the mean CT number determined over an area of $20 \mathrm{~cm}^{2}$. For comparison with in vivo soft tissue values, CT numbers were determined in two ways for the TM materials (using the standard prostate CT protocol supplied by Siemens). First, beam-hardening was simulated by centering the samples in the center opening of a CT phantom (Model 461 A, Gammex/RMI, Middleton, WI) having two $2.5 \mathrm{~cm}$ diameter simulated bone cylinders in two of the four openings for inserts; a cylindrical acrylic block holding the TM materials displaced air in the central opening in the CT phantom. Second, to determine the effect on CT numbers of the beamhardening, the same prostate scan protocol was used when the TM materials were alone during scanning (no CT phantom).

\section{Long-term stability test}

To investigate if water or solute diffusion occurs across the interfaces between two different TM materials, resulting in significant change in physical properties, the characteristic parameters were monitored in the long-term stability phantoms over periods of about 3 months for each imaging modality. $\mathrm{T} 1$ and $\mathrm{T} 2$ relaxation times, ultrasonic propagation speeds, and attenuation coefficients and CT numbers were

TABLE VIII. T2 relaxation times in ms for TM materials measured on a 40 $\mathrm{MHz}$ relaxometer. The uncertainties corresponding to a specific value of $2 \tau$ involve random error only. Instrumental errors may cause the variations with $2 \tau$. Compare means values (bottom row) with corresponding tissue T2 values in column six of Table I.

\begin{tabular}{cccc}
\hline \hline $2 \tau(\mu \mathrm{s})$ & TM prostate & TM muscle & Alternative TM fat \\
\hline 25 & $84.2 \pm 0.2$ & $37.4 \pm 0.1$ & $154.8 \pm 0.4$ \\
125 & $91.1 \pm 0.3$ & $39.1 \pm 0.3$ & $154.6 \pm 0.7$ \\
250 & $91.5 \pm 0.5$ & $35.3 \pm 0.3$ & $149.6 \pm 2.9$ \\
500 & $85.3 \pm 1.0$ & $35.1 \pm 0.5$ & $158.6 \pm 1.6$ \\
mean \pm s.d. & $88.0 \pm 3.8$ & $36.7 \pm 1.9$ & $154.4 \pm 3.7$ \\
\hline \hline
\end{tabular}

TABLE IX. $\mathrm{T} 1_{\text {scanner }}$ relaxation times for $\mathrm{TM}$ materials measured using a 1.5 T GE Signa MRI scanner. Compare values with T1's for corresponding real tissues in Table I.

\begin{tabular}{lc}
\hline \hline \multicolumn{1}{c}{ Sample } & T1 $1_{\text {scanner }}(\mathrm{ms})$ \\
\hline TM prostate & $1032 \pm 8$ \\
TM muscle & $750 \pm 2$ \\
TM fat (oil+ polyurethane) & $306 \pm 15$ \\
Alternative TM fat (pure oil) & $302 \pm 16$ \\
\hline \hline
\end{tabular}

determined at periodically. This was done for each of the two different TM materials in each of the three test phantoms (see Fig. 1) as well as the control phantoms, each of the latter containing a single TM material.

MR relaxation times $\mathrm{T} 1_{\text {scanner }}$ and $\mathrm{T} 2_{\text {scanner }}$ were measured using a 1.5T GE Signa MRI scanner. The subscript "scanner" distinguishes these values from $\mathrm{T} 1$ and $\mathrm{T} 2$ measured using a relaxometer, the relaxometer values being presumably more accurate. To measure $\mathrm{T} 1_{\text {scanner }}$, six $\mathrm{T} 1$-weighted images were obtained with an echo time (TE) of $15 \mathrm{~ms}$ and repetition times (TR) of 116, 250, 500, 1000, 2000, and 4000 $\mathrm{ms}$. Regions of interest were designated for each of the two component TM materials in all three phantoms and the mean pixel values along with the standard deviations recorded. Data were curve-fitted to an exponential of the form of Eq. (1). $\mathrm{T} 22_{\text {scanner }}$ was measured by using a CPMG pulse sequence with $\mathrm{TR}=2000 \mathrm{~ms}$ and echos acquired at 20, 40, 60, and 80 $\mathrm{ms}$. These data were curve-fitted to an equation of the form of Eq. (2). It must be noted that the values for $\mathrm{T} 2{ }_{\text {scanner }} \mathrm{ob}-$ tained are significantly lower than the $\mathrm{T} 2$ values obtained via spectrometer measurements. This lowering exists because $\mathrm{T} 2_{\text {scanner }}$ was measured using a multi-echo sequence where the successive $180^{\circ}$ refocusing pulses are not exact. Hence, the spins towards the edge of the slice may or may not detect the $180^{\circ}$ pulse. As a result, the slice thickness effectively decreases with each successive $180^{\circ}$ pulse and there is a loss of signal with each successive echo. The assumption is made that $\mathrm{T} 2_{\text {scanner }}$ is a sufficiently strong function of the actual $\mathrm{T} 2$ that long-term invariance of $\mathrm{T} 2$ scanner implies the same for $\mathrm{T} 2$.

The ultrasonic propagation speeds and attenuation coefficients and CT numbers were measured in the same manner as previously described in this section for the long-term stability phantoms. In the case of ultrasound, the phantom was placed between the transmitting and receiving transducers in such a way that the ultrasound beam passed through only one of the two TM materials in the phantom. This was then re-

TABLE X. T2 $2_{\text {scanner }}$ relaxation times for TM materials measured using a $1.5 \mathrm{~T}$ Ge Signa MRI scanner. Note that $\mathrm{T}_{2}$ scanner values are expected to greatly underestimate actual T2's. Best estimates of actual T2's are given in Table VIII.

\begin{tabular}{lc}
\hline \hline \multicolumn{1}{c}{ Sample } & T2 $2_{\text {scanner }}(\mathrm{ms})$ \\
\hline TM prostate & $44.3 \pm 0.1$ \\
TM muscle & $19.1 \pm 0.1$ \\
TM fat (oil+ polyurethane) & $30 \pm 1$ \\
Alternative TM fat (pure oil) & $40 \pm 3$ \\
\hline \hline
\end{tabular}


TABLE XI. Ultrasound attenuation coefficients, propagation speeds, and relative backscatter levels of TM materials measured at $22{ }^{\circ} \mathrm{C}$. Note: values of attenuation coefficient $\div$ frequency are shown in parentheses. Compare propagation speed values with those for corresponding tissues in Table II. (Note: No values of propagation speed were found for real prostate; values for liver are shown in Table II as possibly relevant to prostate, both being glands.) Compare values for attenuation coefficient $\div$ frequency with those for real tissues in Table III; again no values for real prostate were found in the literature, and liver values are shown in Table III.

\begin{tabular}{|c|c|c|c|c|c|c|}
\hline \multirow[b]{2}{*}{ Material } & \multicolumn{4}{|c|}{$\begin{array}{l}\text { Ultrasound attenuation coefficient }(\mathrm{dB} / \mathrm{cm}) \\
\text { (Attenuation coefficient } \div \text { frequency) }(\mathrm{dB} / \mathrm{cm} / \mathrm{MHz})\end{array}$} & \multirow{2}{*}{$\begin{array}{l}\text { Propagation } \\
\text { speed }(\mathrm{m} / \mathrm{s})\end{array}$} & \multirow{2}{*}{$\begin{array}{c}\text { Relative } \\
\text { backscatter } \\
\text { level }(\mathrm{dB})\end{array}$} \\
\hline & $2.5 \mathrm{MHz}$ & $4.5 \mathrm{MHz}$ & $6.2 \mathrm{MHz}$ & $8.0 \mathrm{MHz}$ & & \\
\hline TM prostate & $\begin{array}{c}0.97 \pm 0.20 \\
(0.39 \pm 0.08)\end{array}$ & $\begin{array}{c}1.62 \pm 0.20 \\
(0.36 \pm 0.04)\end{array}$ & $\begin{array}{c}2.41 \pm 0.20 \\
(0.37 \pm 0.03)\end{array}$ & $\begin{array}{c}3.13 \pm 0.20 \\
(0.39 \pm 0.03)\end{array}$ & $1537 \pm 2$ & 0 \\
\hline TM muscle & $\begin{array}{l}2.25 \pm 0.20 \\
(0.9 \pm 0.08)\end{array}$ & $\begin{array}{c}3.48 \pm 0.20 \\
(0.77 \pm 0.04)\end{array}$ & $\begin{array}{c}4.61 \pm 0.20 \\
(0.71 \pm 0.03)\end{array}$ & $\begin{array}{c}5.92 \pm 0.20 \\
(0.74 \pm 0.03)\end{array}$ & $1544 \pm 2$ & +6 \\
\hline $\begin{array}{l}\text { TM fat (oil + } \\
\text { polyurethane) }\end{array}$ & $3.86 \pm 0.20$ & $5.48 \pm 0.20$ & $7.46 \pm 0.20$ & $10.07 \pm 0.20$ & $1468 \pm 2$ & +9 \\
\hline $\begin{array}{l}\text { Alternative TM } \\
\text { fat (pure oil) }\end{array}$ & $\begin{array}{c}(1.04 \pm 0.08) \\
(0.16 \pm 0.08)\end{array}$ & $(0.24 \pm 0.04)$ & $\begin{array}{l}(1.20 \pm 0.03) \\
(0.34 \pm 0.03)\end{array}$ & $\begin{array}{l}(1.20 \pm 0.03) \\
(0.49 \pm 0.03)\end{array}$ & $1464 \pm 2$ & $\ldots$ \\
\hline
\end{tabular}

peated for the second TM material in the phantom. The CT number was monitored for each TM material in each test cylinder containing two materials, along with the CT number in control cylinders containing a single material.

\section{RESULTS}

\section{A. MR}

\section{MR relaxometer measurements}

$\mathrm{T} 1$ and T2 values are shown in Tables VII and VIII, respectively. T2 times were found to vary only a few percent with $2 \tau$, the time between successive echoes in the CPMG sequence; the last row in Table VIII shows means and standard deviations. The uncertainties in the $\mathrm{T} 1$ measurements were determined by propagating the standard deviation of means of $M(t)$ values. The inversion recovery experiment was repeated ten times for each $\mathrm{T} 1$ determination. Thus,

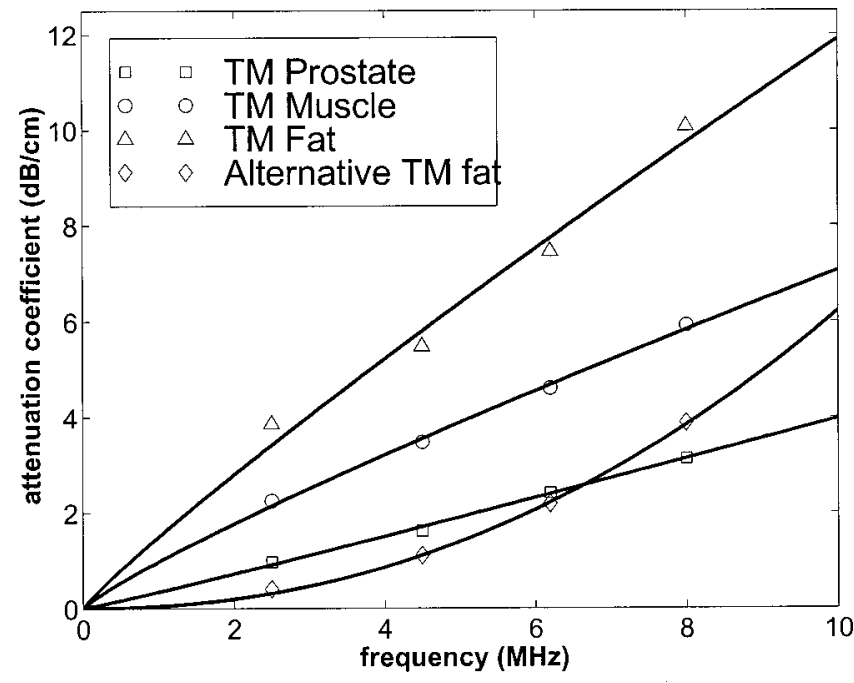

FIG. 2. Ultrasound attenuation dependence on frequency. The data was fitted to the curve of the form $\alpha=\alpha_{0} f^{n}$ where $\alpha$ is the attenuation coefficient, $\alpha_{0}$ is a constant, and $f$ is the frequency. The values obtained for $n$ are $1.06,0.86$, 0.90 , and 2.16 for TM prostate, TM muscle, TM fat, and alternative TM fat, respectively. The uncertainty for all values is about $\pm 0.2 \mathrm{~dB} / \mathrm{cm}$. there were ten values of $M(t)$ for each time $t$. It was assumed that the uncertainty in $M(t)$ is independent of $t$, and the uncertainty in the mean of $M(t)$ for any $t$ was set equal to the standard deviation of the mean for very long $t(t$ $\gg 5 \mathrm{~T} 1)$. Then the uncertainty in $\mathrm{T} 1$ was determined using Eq. (1) with arbitrary clock zero $\left(t \rightarrow t-t_{0}\right)$ and the methods presented in Ref. 24. It must be noted that, although the samples reached thermal equilibrium in a water bath at $21{ }^{\circ} \mathrm{C}$ before insertion into the spectrometer, there will have been a temperature rise during data acquisition $\left(\sim 2{ }^{\circ} \mathrm{C}\right)^{23}$ since the $40 \mathrm{MHz}$ spectrometer is maintained at $40^{\circ} \mathrm{C}$. Values of $\mathrm{T} 1$ and $\mathrm{T} 2$ are assumed to apply at about $22^{\circ} \mathrm{C}$. Data obtained from the T2 experiment was curve-fitted in a least squares manner to Eq. (2) to obtain T2, and uncertainties were found in the same fashion as in the case of $\mathrm{T} 1$.

\section{MR scanner measurements}

$\mathrm{T} 1_{\text {scanner }}$ and $\mathrm{T} 2_{\text {scanner }}$ times for the $\mathrm{TM}$ materials are shown in Tables IX and X, respectively. A region of interest was designated in each of the T1- and T2-weighted images and the mean pixel value was measured along with the standard deviation. The data were then fit to Eq. (1) for T1weighted images and Eq. (2) for T2-weighted images.

\section{B. Ultrasound}

The measured acoustic propagation speed and ultrasonic attenuation coefficient values at $22^{\circ} \mathrm{C}$ for the $\mathrm{TM}$ materials are shown in Table XI. Also shown are the relative backscatter levels. Ultrasound attenuation was measured at 2.5, 4.5, 6.2 , and $8.0 \mathrm{MHz}$. Figure 2 highlights the dependence of attenuation on frequency for each of the TM materials. Least-squares curve-fitting was done for each material assuming a functional form of $\alpha=\alpha_{0} f^{n}$, where $\alpha_{0}$ and $n$ are constants and $f$ is the frequency.

\section{C. $\mathrm{CT}$}

Values of measured effective x-ray attenuation coefficients for beams of different qualities and $\mathrm{CT}$ numbers for 
TABLE XII. Measured attenuation coefficients and CT numbers of TM materials. The filtration and effective energies $\mathrm{E}$ of the laboratory $\mathrm{x}$-ray beams are shown. CT numbers were measured at $133 \mathrm{kVp}$ (average energy $=78 \mathrm{keV}$ ). The fourth column lists CT numbers without beam hardening using the prostate scanning protocol. The right-most column shows CT numbers in which patient-like beam hardening is represented with a 461A CT phantom (Gammex/RMI, Middleton, WI); again, the prostate protocol was employed. Compare CT numbers in the right-most column with human values in Table IV.

\begin{tabular}{|c|c|c|c|c|}
\hline \multirow[b]{2}{*}{ Material } & \multicolumn{2}{|c|}{ Attenuation coefficient $\left(\mathrm{cm}^{-1}\right)$} & \multirow{2}{*}{$\begin{array}{c}\text { CT no. } \\
\text { with no beam } \\
\text { hardening }\end{array}$} & \multirow{2}{*}{$\begin{array}{l}\text { CT no. } \\
\text { with beam } \\
\text { hardening }\end{array}$} \\
\hline & $\mathrm{M}-150, \mathrm{E}=67 \mathrm{keV}$ & $\mathrm{M}-200, \mathrm{E}=100 \mathrm{keV}$ & & \\
\hline TM prostate & $0.204 \pm 0.008$ & $0.173 \pm 0.008$ & $47 \pm 2$ & $43 \pm 12$ \\
\hline TM muscle & $0.214 \pm 0.009$ & $0.179 \pm 0.008$ & $96 \pm 5$ & $86 \pm 12$ \\
\hline TM fat (oil+polyurethane) & $\ldots$ & $\ldots$ & $-115 \pm 3$ & $\ldots$ \\
\hline Alternative TM fat (pure oil) & $0.179 \pm 0.008$ & $0.160 \pm 0.007$ & $-117 \pm 3$ & $-104 \pm 11$ \\
\hline
\end{tabular}

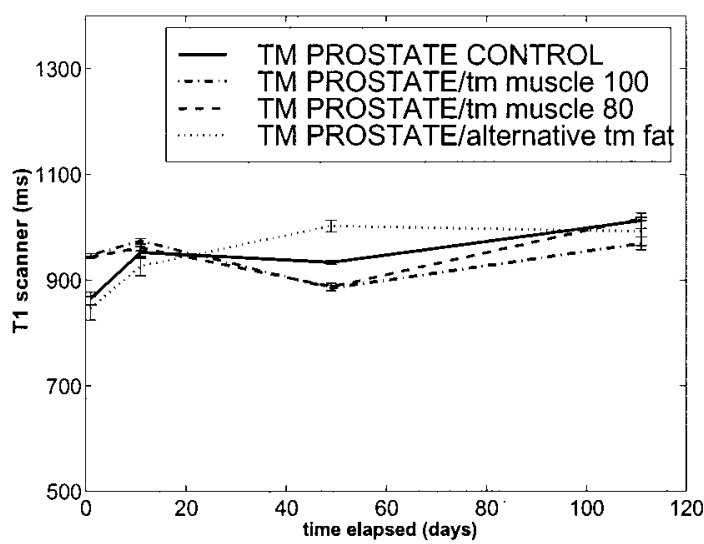

(a)

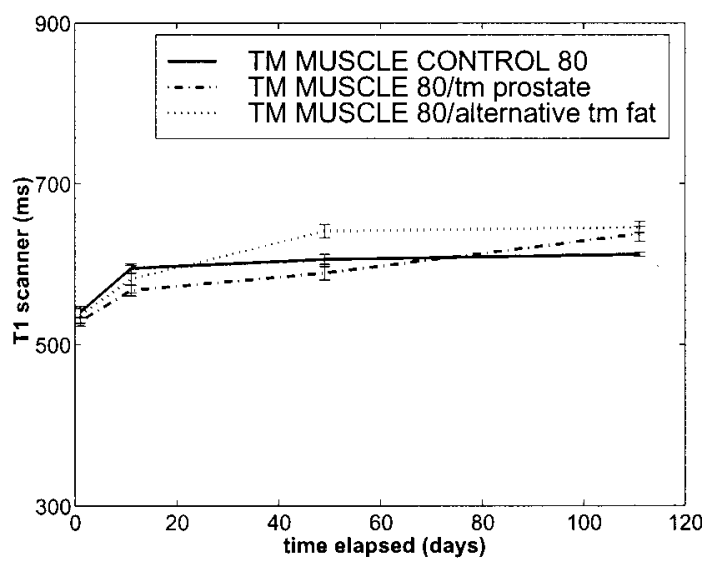

(c)

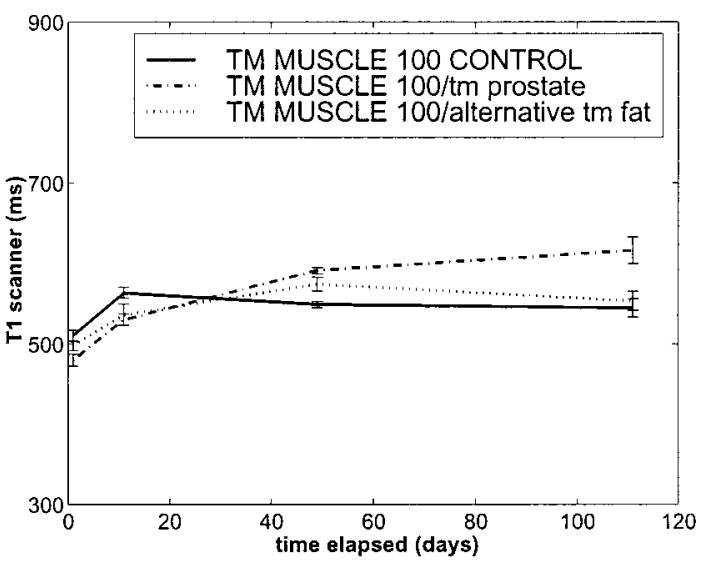

(b)

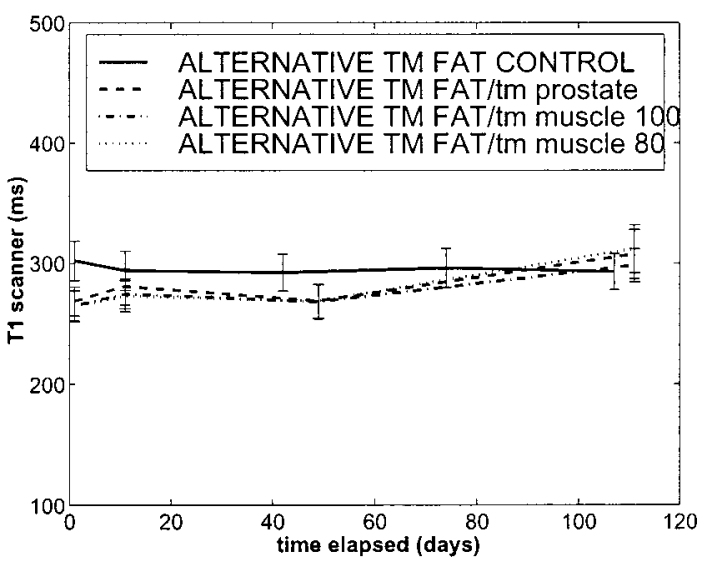

(d)

FIG. 3. Long-term stability test of T1 in TM material controls and TM materials in direct contact with each other. Periodically determined T1 values are shown over a period of 110 days. (a) T1 values for TM prostate are shown for four situations: isolated TM prostate (control); contact with TM muscle when concentrations of $\mathrm{Cu}^{++}$-EDTA is the same in both at the outset (tm muscle 100); contact with TM muscle when the concentration of $\mathrm{Cu}^{++}$-EDTA in TM muscle is $80 \%$ of that in TM prostate at the outset (TM muscle 80); contact with alternative TM fat. All curves agree rather well with one another. (b) T1 values for TM muscle when the initial concentration of $\mathrm{Cu}^{++}$in TM muscle is the same as for TM prostate (TM muscle 100) for three cases: isolated TM muscle 100 (control); contact with TM prostate; contact with TM fat. Notice that, for the case of TM muscle 100 in contact with TM prostate, T1 steadily increases relative to TM muscle control suggesting long diffusion of $\mathrm{Cu}^{++}$-EDTA from TM muscle 100 to TM prostate corresponding to the initial concentration being too high in the TM muscle. (c) T1 values for TM muscle when the initial concentration of $\mathrm{Cu}^{++}$-EDTA in TM muscle is $80 \%$ of that in TM prostate for three cases: isolated TM muscle 80 (control); contact with TM prostate; contact with alternative TM fat. All curves agree rather well with one another, indicating that TM muscle 80 is more suitable than TM muscle 100 for direct contact stability. (d) T1 values for alternative TM fat for four cases: isolated alternative TM fat (control); contact with TM prostate; contact with TM muscle 100; contact with TM muscle 80. All curves agree well, indicating that solute exchange is not significant. 


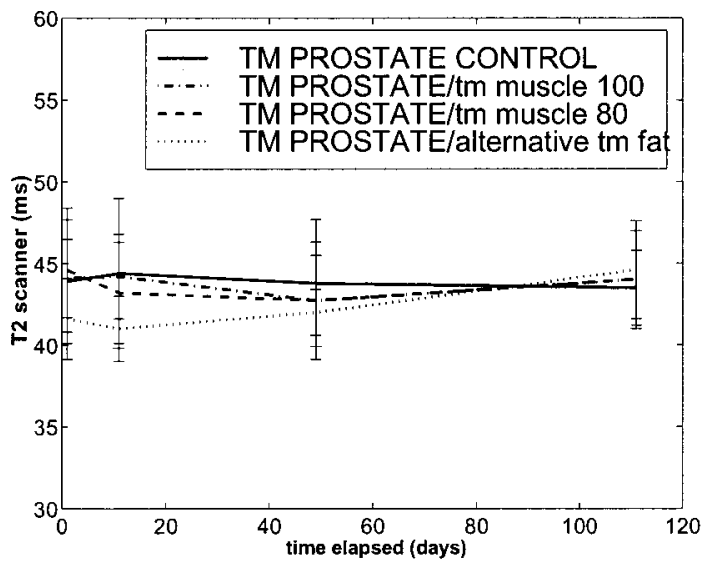

(a)

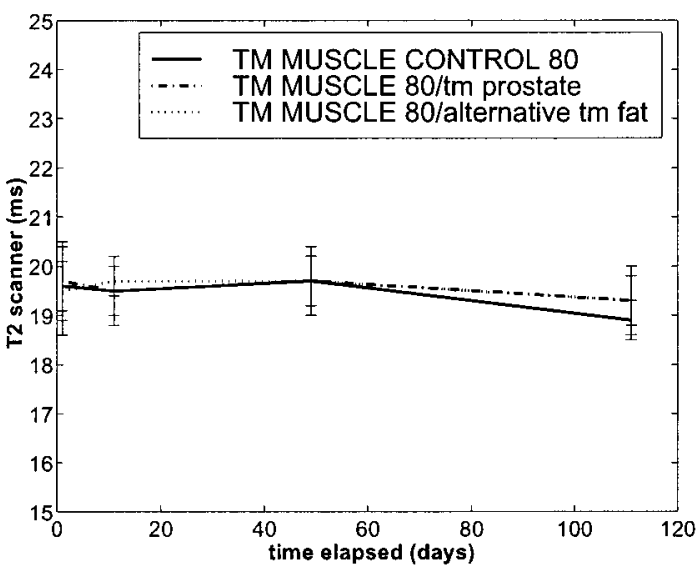

(c)

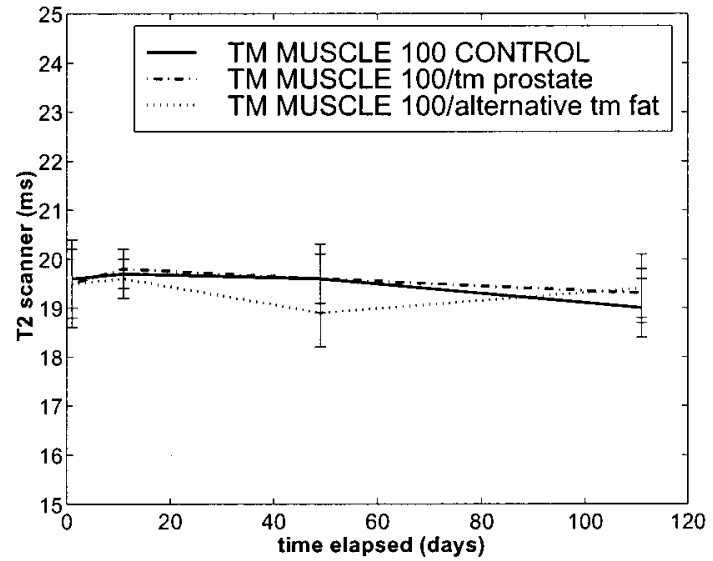

(b)

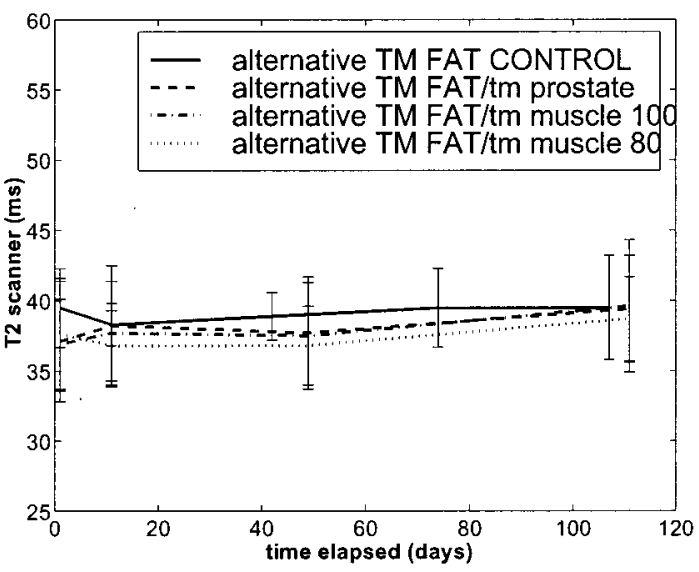

(d)

FIG. 4. Long-term stability results for the $\mathrm{T} 2_{\text {scanner }}$ parameter for $\mathrm{TM}$ material controls and in direct contact with each other. $\mathrm{T} 2_{\text {scanner }}$ for all materials is stable. See discussion in Fig. 3 caption for the definitions of TM muscle 100 and TM muscle 80.

the three TM materials are shown in Table XII. The relative CT numbers are in the ranges observed on CT images of patients which include prostate, muscle, and fat.

\section{Long-term stability}

Figures 3-7 show the results of the long-term stability measurements for MRI, US, and CT. There were no changes in the US and CT parameters as well as the $\mathrm{T} 2_{\text {scanner }}$ values of the materials (see Figs. 4-7). Each set of six long-term stability phantoms included three of the form shown in Fig. 1 and three "control" samples, each of the latter containing one of the three TM materials tested.

\section{DISCUSSION}

Due to the large number (six) of parameters involved in establishing that each of the three materials mimics the corresponding tissue, in addition to the requirement that the materials be stable in direct contact, it is reasonable that agreement between material and tissue values will not be as close for all parameters as could be attained under less demanding circumstances.
MR relaxometer measurements of the $\mathrm{T} 1$ relaxation times for the TM materials show reasonably good agreement with the corresponding published values. The T1 for TM prostate measured was $937 \pm 13 \mathrm{~ms}$ at $40 \mathrm{MHz}$ and $22^{\circ} \mathrm{C}$. Grodd et al. ${ }^{1}$ have found $\mathrm{T} 1$ for human prostate to be $808 \mathrm{~ms}$ at 20 $\mathrm{MHz}$ and $40^{\circ} \mathrm{C}$. Taking T1 for nonfat tissue to be approximately proportional to the square root of the frequency, ${ }^{27}$ and to decrease by about $3 \%$ as the temperature decreases by $3{ }^{\circ} \mathrm{C}\left(40{ }^{\circ} \mathrm{C}\right.$ to $\left.37^{\circ} \mathrm{C}\right),{ }^{27}$ the adjusted $\mathrm{T} 1$ from Grodd et al. ${ }^{1}$ is about $1100 \mathrm{~ms}$. Our T1 value of $937 \mathrm{~ms}$ for TM prostate is about $15 \%$ lower. The measured T1 time for TM muscle was $686 \pm 9$ and falls in the range of $650-800 \mathrm{~ms}$ measured by Borghi et al. ${ }^{5}$ Three $\mathrm{T} 1$ values for fat at body temperature in Table I lie in the $200 \mathrm{~ms}$ range and show little frequency dependence. Our measured value for alternative TM fat, $207 \pm 6 \mathrm{~ms}$, agrees reasonably well with the values for real soft tissue shown in Table I.

Relaxometer T2 times shown in Table VIII were found to vary little with the echo time $(2 \tau)$. The average T2 for TM prostate was $88.0 \mathrm{~ms}$ with a standard deviation of $1.2 \mathrm{~ms}$. Similarly, the average T2 values for TM muscle and TM fat were 36.7 and $154.4 \mathrm{~ms}$, respectively, with standard devia- 


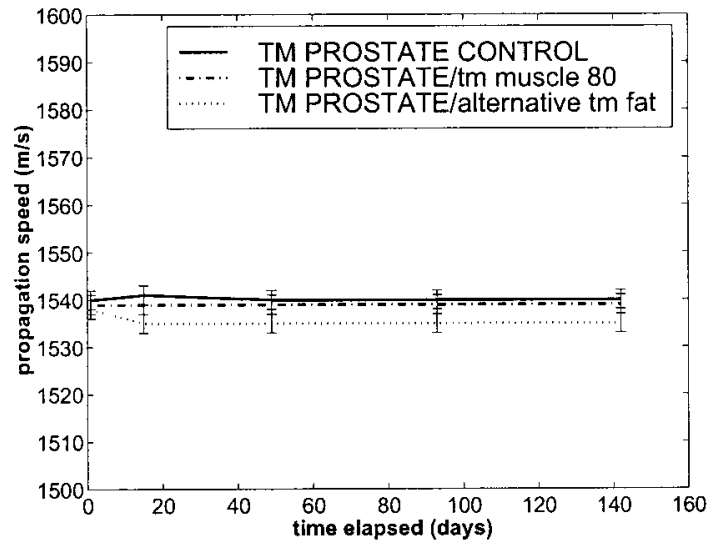

(a)

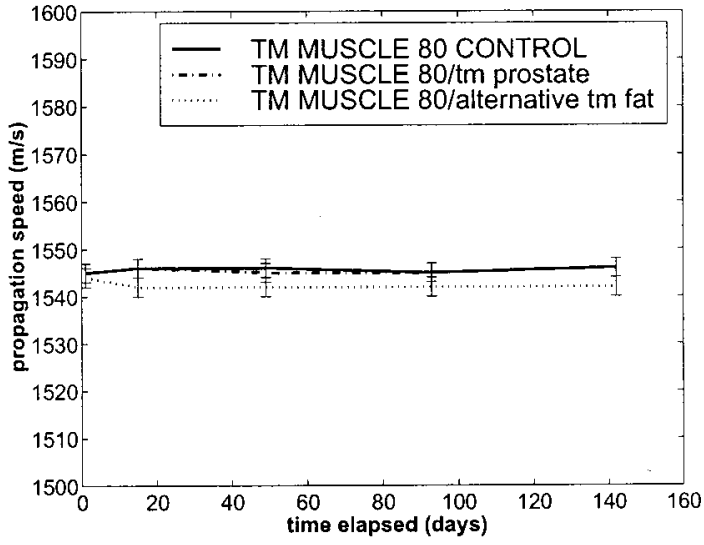

(b)

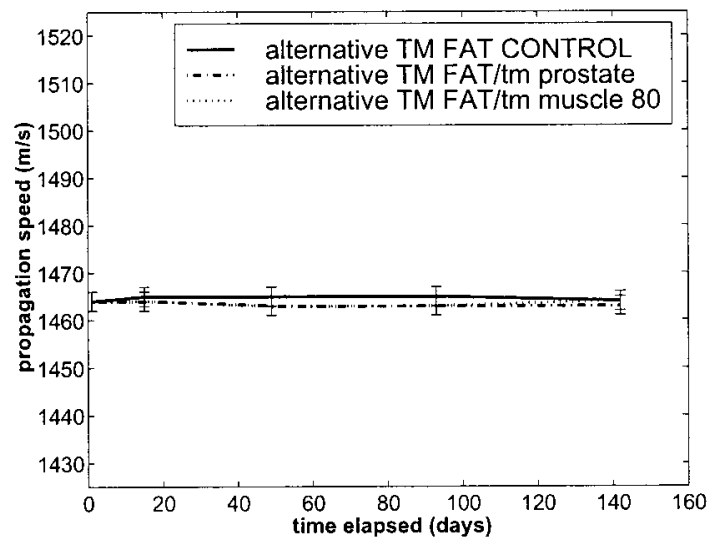

(c)

FIG. 5. Long-term stability of the speed of sound in TM material controls and TM materials in direct contact with each other. (a) TM prostate control and in contact with TM muscle 80 and alternative TM fat; (b) TM muscle 80 control and in contact with TM prostate and alternative TM fat; and (c) alternative TM fat control and in contact with TM prostate and TM muscle 80 .

tions of 0.7 and $3.4 \mathrm{~ms}$. Except for the fat T2 measured by Nyman et al., ${ }^{7}$ good agreement is found between the measured values for the TM materials and the literature values for actual human tissue shown in Table I. Note that tissue T2 values reported by Bottomly et al. ${ }^{27}$ indicate little frequency dependence. Also, the temperature dependence of tissue T2 values is much smaller than for T1 values. ${ }^{8}$

The average ultrasound attenuation coefficient slopes for TM prostate and TM muscle were found to be 0.38 $\mathrm{dBcm}^{-1} \mathrm{MHz}^{-1}$ and $0.79 \mathrm{dBcm}^{-1} \mathrm{MHz}^{-1}$, respectively. The measured ultrasound attenuation coefficients agree reasonably well with actual human tissue values shown in Table III. (Note that values for prostate were not found in the literature and those for human liver in vivo are shown in Table III instead.) The attenuation coefficient $\div$ frequency values in muscle are a little higher than in TM muscle, and TM prostate has a value similar to that for liver. Figure 2 shows attenuation coefficients and curve-fits for the TM materials as a function of frequency. The values of $n$ obtained from the curve-fitting process are $1.06,0.86$, and 0.90 for TM prostate, TM muscle, and TM fat, respectively. As is the case for soft tissues, the attenuation coefficient is nearly proportional to the frequency for TM prostate $(n=1.06)$, and $n$ is in the range of 1 for TM muscle $(n=0.86)$. The value of $n$ is 2.16 for alternative TM fat (pure oil), a value that is close to the value of 1.7 for breast fat ${ }^{14}$ and $n=0.90$ for oil and the polyurethane mesh together (TM fat).

The propagation speeds in the TM materials are in the soft tissue range. TM prostate was found to have a speed of sound of $1537 \mathrm{~m} / \mathrm{s}$. The average measured value for TM muscle was $1544 \mathrm{~m} / \mathrm{s}$ at $22^{\circ} \mathrm{C}$ while that for skeletal muscle has been found to be $1580 \mathrm{~m} / \mathrm{s}$ at $37^{\circ} \mathrm{C} .{ }^{9}$ For TM fat the average measured propagation speed of sound was $1468 \mathrm{~m} / \mathrm{s}$ and human fat has been found to have a value of $1476 \mathrm{~m} / \mathrm{s}$ at $35^{\circ} \mathrm{C} .{ }^{11}$

The x-ray attenuation coefficients were measured with two different beam qualities on the ADCL system. The CT numbers were measured with a clinical Siemens CT scanner using a $\mathrm{kVp}$ of $133 \mathrm{kVp}$ (mean energy of $78 \mathrm{keV}$ ). The degree of correspondence of CT numbers between the tissue mimicking materials and in vivo human tissue values can be assessed using Tables IV and XII. The level of agreement is very good, comparing $\mathrm{CT}$ numbers attained under identical conditions (same scanner, $\mathrm{kVp}$, and mean photon energy). For TM prostate, the CT number with patient-like beam 


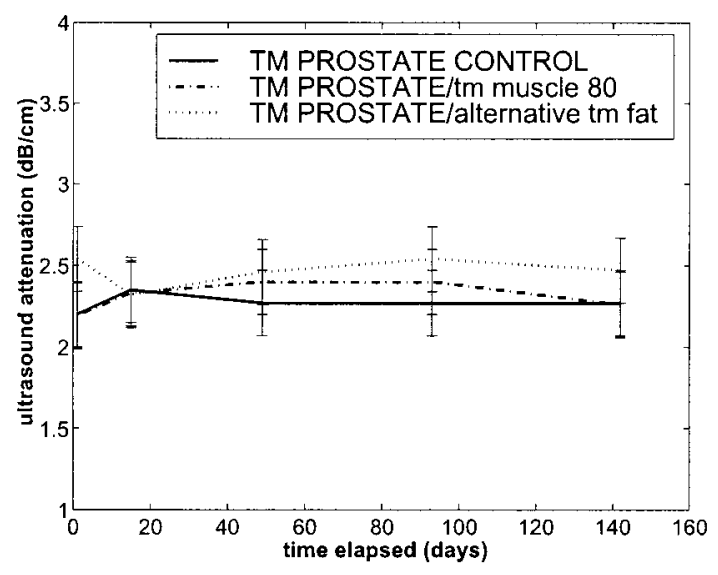

(a)

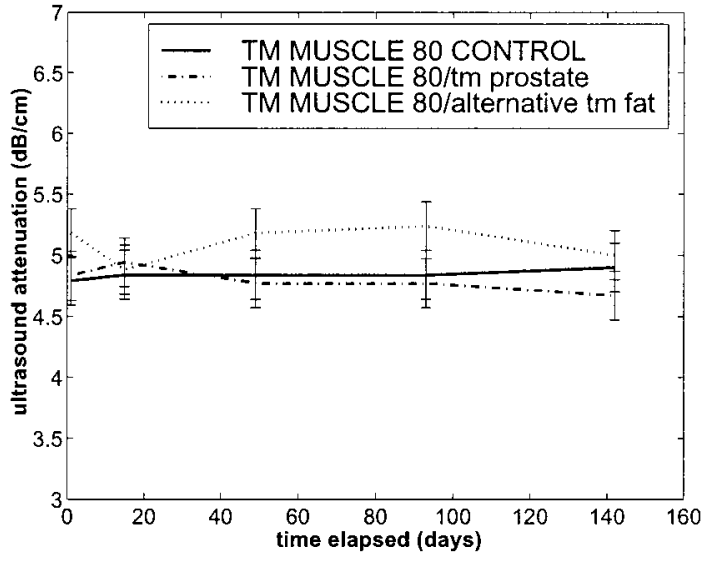

(b)

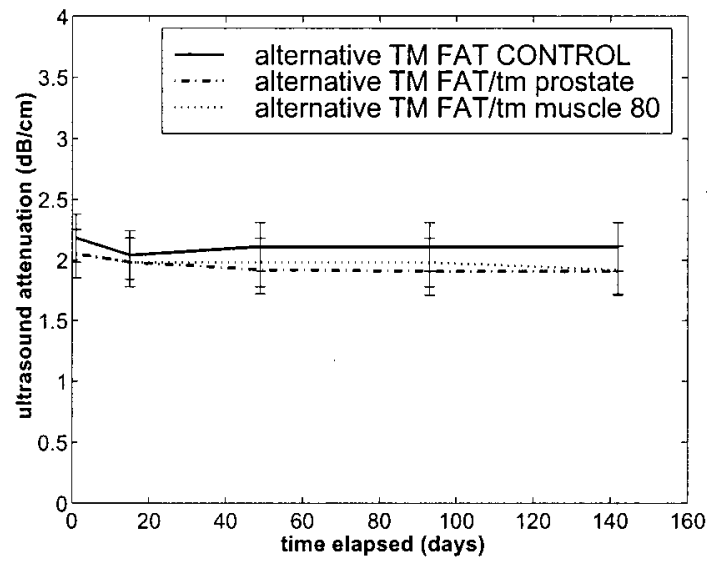

(c)

FIG. 6. Long-term stability of ultrasound attenuation at $6.2 \mathrm{MHz}$ in TM material controls and TM materials in direct contact with each other. (a) TM prostate control and in contact with TM muscle 80 and alternative TM fat; (b) TM muscle control 80 and in contact with TM prostate and alternative TM fat; and (c) alternative TM fat control and in contact with TM prostate and TM muscle 80.

hardening is $43 \pm 12$, while for human tissue, CT number $=45 \pm 17$. For TM muscle, the CT number with beam hardening is $86 \pm 12$ compared with $77 \pm 14$ for in vivo muscle. For alternative TM fat (oil only), the CT number with beam hardening is $-104 \pm 11$ while for in vivo human fat, CT number $=-97 \pm 9$. Thus, the contrast between TM materials mimics that for the actual in vivo human tissues rather well.

Long-term stability of $\mathrm{T} 1$ is consistent with all results shown in Fig. 3 except for the case of T1 for TM muscle 100 when in contact with TM prostate. (TM muscle 100 refers to TM muscle with initial $\mathrm{Cu}^{++}$-EDTA concentration equal to that in TM prostate.) T1's for TM muscle 100 in contact with TM prostate [see Fig. 3(b)] become steadily larger than those for TM muscle 100 control. In comparison, T1 for TM muscle 80 in contact with TM prostate shows less change relative to TM muscle 80 control. Thus, probably the best choice for representation of muscle is TM muscle 80 where the net concentration of $\mathrm{Cu}^{++}$-EDTA is $80 \%$ of that in TM prostate.

Long-term monitoring of the propagation speed and US attenuation show that the TM materials can be placed in direct contact with each other without change in these properties (see Figs. 5 and 6). For the US propagation speed, the greatest changes relative to the control samples were seen in TM prostate and TM muscle while they were in contact with alternative TM fat. This variation was $4 \mathrm{~m} / \mathrm{s}$ in both cases. The variation in the US attenuation at $6.2 \mathrm{MHz}$ is again the largest for the TM prostate and TM muscle samples in contact with alternative TM fat. This variation is still $<10 \%$ of the value exhibited by the control samples. CT numbers were found to vary by no more than 5 units, which is not clinically significant. Thus, overall the stability of the described TM materials in direct contact with each other was remarkable and this proves that they can be placed together in an anthropomorphic phantom.

\section{SUMMARY AND CONCLUSIONS}

Materials for quantitatively mimicking soft tissues relevant to a multi-imaging modality (MRI, US, CT) prostate phantom have been developed. The soft tissues mimicked are prostate, muscle, and fat. Measurements of the T1 and T2 


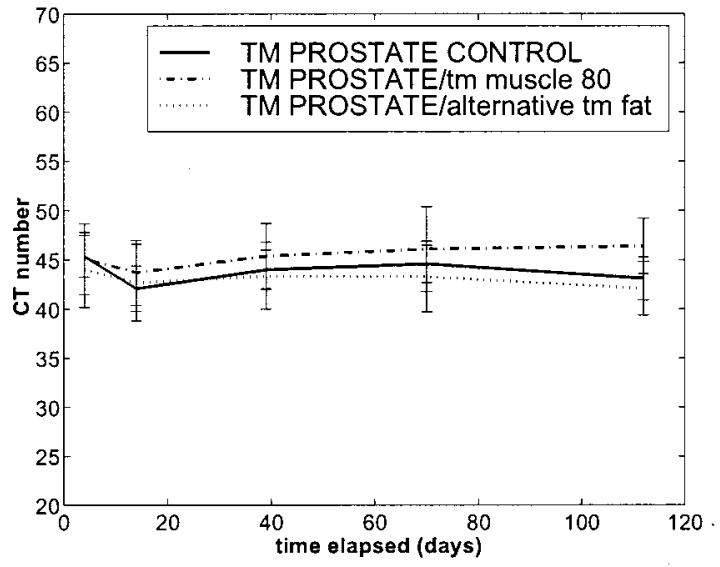

(a)

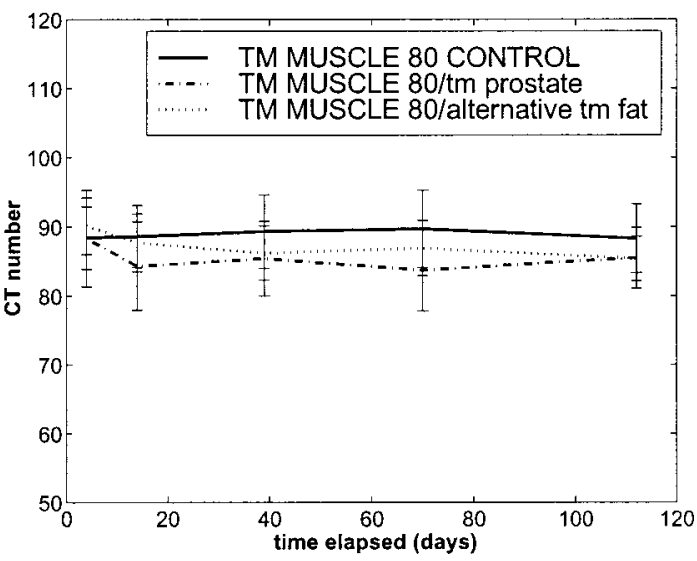

(b)

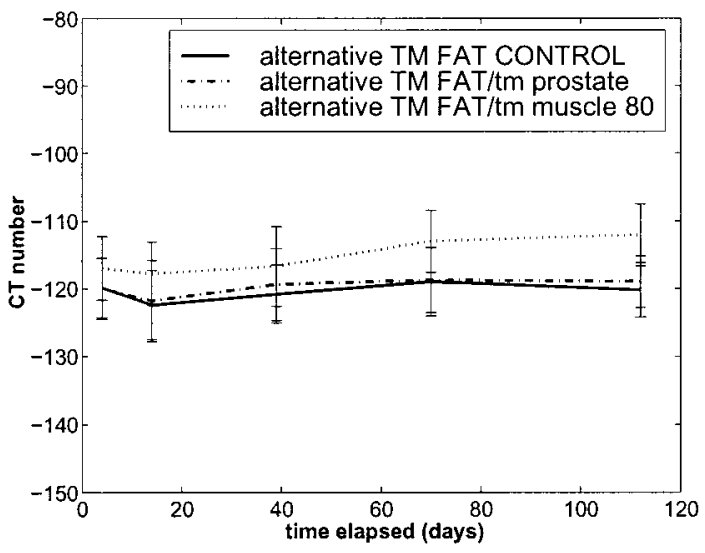

(c)

FIG. 7. Long-term stability of CT numbers in TM material controls and TM materials in direct contact with each other. The phantom cylinders were not surrounded by a beam-hardening layer. (a) TM prostate control and in contact with TM muscle and alternative TM fat; (b) TM muscle control and in contact with TM prostate and alternative TM fat; and (c) alternative TM fat control and in contact with TM prostate and TM muscle.

relaxation times indicate reasonable agreement with published values of actual human soft tissue in vivo. Ultrasound propagation speeds and attenuation coefficients for the developed materials were also matched with the literature values. The CT numbers lay within the range seen for these soft tissues clinically. The various parameters measured on each of the three imaging modalities agree within reason with real human tissue data. Some deviation from the published values had to be accepted in order to make these materials useful for the three imaging modalities. We assessed two versions of TM muscle that mimic human muscle tissue. TM muscle containing $80 \%$ of the concentration of $\mathrm{Cu}^{++}$-EDTA compared with that in TM prostate may provide more long-term stability when in contact with other TM materials.

The developed TM materials can be used in an anthropomorphic phantom where they will be placed in direct contact with one another. Production of such anthropomorphic phantoms can now proceed.

\section{ACKNOWLEDGMENTS}

This work was supported in part by NIH Grant No. R42GM54377 and a University of Wisconsin Industry Relations Grant. The authors are grateful to John R. Vetter of the
University of Wisconsin, Medical Physics Department for providing the Gammex/RMI CT phantom used for realistic beam-hardening in the determination of CT numbers for the TM materials and for providing advice on the use of the CT phantom. We are also grateful to David Pearson at the University of Wisconsin, ADCL for help in x-ray attenuation coefficient measurements of the TM materials.

\footnotetext{
${ }^{a)}$ Current address: UT M. D. Anderson Cancer Center, Box 94, 1515 Holcombe Blvd., Houston, TX 77030; Electronic mail: wdsouza@mail.mdanderson.org

${ }^{1}$ W. von Grodd and W. G. H. Schmitt, "Protonenrelaxationsverhalten menschlicher und tierischer Gewebe in vitro," Anderungen bei Autolyse und Fixierung, Fortschr Röntgenstr. 139, 233-240 (1983).

${ }^{2}$ L. Kjaer, C. Thomsen, P. Iversen, and O. Henriksen, "In vivo estimation of relaxation processes in benign hyperplasia and carcinoma of the prostate gland by magnetic resonance imaging,"' Magn. Reson. Imaging $\mathbf{5}$, 23-30 (1987).

${ }^{3}$ A. LeBlanc, H. Evans, E. Schonfeld, J. Ford, C. Marsh, V. Schneider, and P. Johnson, "Relaxation times of normal and atrophied muscle," Med. Phys. 13, 514-517 (1986).

${ }^{4}$ R. L. Ehman, B. O. Kjos, H. Hricak, R. C. Brasch, and C. B. Higgins, "Relative intensity of abdominal organs in MR images," J. Comput. Assist. Tomogr. 9, 315-319 (1985).

${ }^{5}$ L. Borghi, F. Savoldi, R. Scelsi, and M. Villa, "Nuclear magnetic resonance response of protons in normal and pathological human muscles," Exp. Neurol. 81, 89-96 (1983).
} 
${ }^{6}$ M. Just and M. Thelen, "'Tissue Characterization with T1, T2, and proton density values: results in 160 patients with brain tumors,' Radiology 169, 779-785 (1988).

${ }^{7}$ R. Nyman, A. Ericsson, A. Hemmingsson, B. Jung, G. Sperber, and K. A. Thuomas, "T1, T2, and relative proton density at $0.35 \mathrm{~T}$ for spleen, liver, adipose tissue, and vertebral body: normal values,', Magn. Reson. Med. 3, 901-910 (1986).

${ }^{8}$ F. R. Duck, Physical Properties of Tissue, A Comprehensive Reference Book (Academic, San Diego, 1990).

${ }^{9}$ B. D. Sollish, "A device for measuring ultrasonic propagation velocity in tissue,' in Ultrasonic Tissue Characterization II, edited by M. Linzer, NBS Spec. Publ. 525 (U.S. GPO, Washington, DC, 1979), pp. 53-56.

${ }^{10}$ B. Rajagopalan, J. F. Greenleaf, P. J. Thomas, S. A. Johnson, and R. C. Bahn, "Variation of acoustic speed with temperature in various exised human tissues studied by ultrasound computerized tomography,' In Linzer, pp. 227-233 (1979).

${ }^{11}$ B. A. Bullen, F. Quaade, E. Olesen, and S. A. Lund, "Ultrasonic reflections used for measuring subcutaneous fat in humans,' Human Biology 37, 375-384 (1965).

${ }^{12}$ D. E. Robinson et al., "Experience in sound speed measurement in liver and spleen,' in Proceedings of Euroson (Finnish Society for Ultrasound in Medicine and Biology, 1987), p. 305.

${ }^{13}$ J. C. Bamber, "Ultrasonic attenuation in fresh human tissues,' Ultrasonics 19, 187-188 (1981).

${ }^{14}$ F. T. D'Astous and F. S. Foster, "Frequency dependence of ultrasound attenuation and backscatter in breast tissue,' Ultrasound Med. Biol. 12, 795-808 (1986).

${ }^{15}$ K. T. Dussik, D. J. Fritch, M. Kyriazidou, and R. S. Sears, "Measurements of articular tissue with ultrasound,' Am. J. Phys. Med. 37, 160165 (1958).

${ }^{16}$ J. Ophir, N. F. Maklad, and R. H. Bigelow, "Ultrasonic Attenuation Measurements of in vivo Human Muscle,' Ultrason. Imaging 4, 290-295 (1982).

${ }^{17}$ K. J. Parker, M. S. Asztely, R. M. Lerner, E. A. Schenk, and R. C. Waag, "In-vivo measurements of ultrasound attenuation in normal or diseased liver,' Ultrasound Med. Biol. 14, 127-136 (1988).
${ }^{18}$ K. J. W. Taylor, C. A. Riely, L. Hammers, S. Flax, G. Weltin, G. GarciaTsao, H. O. Conn, R. Kuc, and K. W. Barwick, "Quantitative US attenuation in normal liver and in patients with diffuse liver disease: Importance of fat,' Radiology 160, 65-71 (1986).

${ }^{19}$ G. D. Fullerton, "Fundamentals of CT Tissue Characterization," in Medical Physics of CT and Ultrasound: Tissue Imaging and Characterization, edited by G. D. Fullerton and J. A. Zagzebski (AIP, New York, 1980), p. 129.

${ }^{20}$ M. D. Mitchell, H. L. Kundel, L. Axel, and P. M. Joseph, “Agarose as a tissue equivalent phantom material for NMR imaging,' Magn. Reson. Imaging 4, 263-266 (1986).

${ }^{21}$ J. R. Rice, R. H. Milbrandt, E. L. Madsen, G. R. Frank, E. J. Boote, and J. C. Blechinger, "Anthropomorphic ${ }^{1} \mathrm{H}$ MRS head phantom,' Med. Phys. 25, 1145-1156 (1998).

${ }^{22}$ E. L. Madsen, G. R. Frank, and F. Dong, “'Liquid or solid ultrasonically tissue-mimicking materials with very low scatter,' Ultrasound Med. Biol. 24, 535-542 (1998).

${ }^{23}$ J. C. Blechinger, E. L. Madsen, and G. R. Frank, "Tissue-mimicking gelatin-agarose gels for use in magnetic resonance imaging,' Med. Phys. 15, 629-636 (1988).

${ }^{24}$ P. R. Bevington, Data Reduction and Error Analysis for the Physical Sciences (McGraw-Hill, New York, 1969), pp. 107-116.

${ }^{25}$ E. L. Madsen, F. Dong, G. R. Frank, B. S. Garra, K. A. Wear, T. Wilson, J. A. Zagzebski, H. L. Miller, K. K. Shung, S. H. Wang, E. J. Feleppa, T. Liu, W. D. O’Brien, Jr., K. A. Topp, N. T. Sanghvi, A. V. Zaitsev, T. J. Hall, J. B. Fowlkes, O. D. Kripfgans, and J. G. Miller, "Interlaboratory comparison of ultrasonic backscatter attenuation and speed measurements," J. Ultrasound Med. 18, 615-631 (1999).

${ }^{26}$ V. A. DelGrosso and C. W. Mader, "Speed of sound in pure water," J. Acoust. Soc. Am. 52, 1442-1446 (1972).

${ }^{27}$ P. A. Bottomley, T. H. Foster, R. E. Argersinger, and L. M. Pfeifer, “A review of normal tissue hydrogen NMR relaxation times and relaxation mechanisms from 1-100 MHz; dependence on tissue type, NMR frequency, temperature, species, excision and age,' Med. Phys. 11, 425448 (1984). 